Bull. Mater. Sci., Vol. 8, No. 5, December 1986, pp. 557-565. (C) Printed in India.

\title{
Glass ceramics containing ferroelectric phases
}

\begin{abstract}
OM PARKASH, DEVENDRA KUMAR* and LAKSHMAN PANDEY
School of Materials Science and Technology, ${ }^{*}$ Department of Ceramic Engineering, Institute of Technology, Banaras Hindu University, Varanasi 221005 , India

MS received 31 March 1986

Abstract. Glass ceramics prepared by controlled crystallization of glasses produce fine dispersion of crystallites in a glassy matrix. Glasses containing a major portion of constituents of a ferroelectric phase produce crystallites of ferroelectric phase in glass through a suitable heat treatment. The amount of network former in the initial glass hàs a profound influence on its crystallization behaviour and microstructure of the resulting ferroelectric glass ceramics. The value of dielectric constant and the nature of ferroelectric to paraelectric transition depend on the crystallite size and volume fraction of the ferroelectric phase. These glass ceramics are transparent for crystallite size less than $0-1 \mu \mathrm{m}$ and exhibit large quadratic-electro-optic effect.
\end{abstract}

Keywords. Glass ceramics; ferroelectric; crystallization; heat treatment.

\section{Introduction}

Stookey (1959) discovered the method of controlled nucleation and crystallization of glass to produce ceramic bodies. Such materials are referred to as glass ceramics (McMillan 1979) in which crystallites of a particular phase are dispersed in a continuous glassy matrix. Their preparation consists of making a homogeneous glass, its shaping in the desired form and finally heat-treating it to produce microcrystalline glass ceramic body. These glass ceramic bodies are free from pores in contrast to conventionally sintered ceramics. Absence of pores imparts them higher mechanical and dielectric breakdown strengths. Glass ceramic bodies having intricate shapes and close tolerance in dimensions can be produced using commercial methods of glass production. This is because the conversion of glass into glass ceramic is rarely accompanied by more than $3-5 \%$ change in volume.

Soon after the discovery of the glass ceramic process, attempts were made to produce glass ceramics having high permittivity, low dielectric loss, high electrical resistance and dielectric breakdown strength by precipitating ferroelectric phases in the glassy matrix (Bergeron 1961; Herczog 1964; Borrelli et al 1965). These materials find applications- as capacitor dielectrics (Herczog 1967), as electronic components (Herczog 1973) and as infrared detectors (Takahashi et al 1975) etc. The ferroelectric phases are generally $\mathrm{ABO}_{3}$ perovskite type where $A$ ion is from first, second and third group and $B$ ion is from second to fifth group of the periodic table.

The ferroelectric perovskites can be produced in the glassy form in the pure state without addition of a network former (Ulrich and Smoke 1966; Glass et al 1978; Nassau et al 1979a, b, 1981). The viscosity of the melt without network former is low. This requires rapid quenching of the melt of the order of $10^{6}$ degrees/sec or more producing only very small thin platelets. On the other hand crystallization of bodies made of glass powder may produce undesirable porous structure. The addition of network formers, such as $\mathrm{SiO}_{2}, \mathrm{~B}_{2} \mathrm{O}_{3}, \mathrm{Al}_{2} \mathrm{O}_{3}$ etc increases the viscosity of the melt. 
This helps in producing a few millimeter thick dises or plates by cooling of the melt at a moderate rate of a few hundred degrees $/ \mathrm{sec}$. The devitrification of a glass to a crystalline phase of the same composition produces crystals of varying sizes which is difficult to control. The glasses containing network formers yield two or more phases during crystallization. The minor phase acts as grain growth inhibitor of the major phase. With this, an exact control of grain size in glass ceramics is possible. Due to these various factors, the glasses prepared from the melts of pure perovskites and the crystalline product obtained therefrom are not yet usable and have academic interest only. In this review, we attempt to present the processing, crystallization and electrical properties of various glass ceramic systems containing ferroelectric phases studied so far. These glass ceramics are prepared from glasses containing network formers.

\section{Processing}

The glasses are prepared by melting batches containing a major amount of constituents of desired ferroelectric phase and an optimum amount of network formers in inert crucibles. The use of inert crucibles is recommended because any contamination during melting may adversely affect the crystallization behaviour of the glass and the dielectric properties of the resulting glass ceramic product (Grossman and Isard 1969a). The melt is quenched by pouring it into a suitably designed mould provided with an arrangement of pressing. The pressing time and temperature are adjusted to avoid the devitrification and development of thermal cracks in the quenched glass body. Fully or semi-automatic arrangements are used for this purpose (Herczog 1964, 1984). The glass melt is transferred to a mechanized glass delivery system designed to ensure reproducible glass forming conditions. It consists of a platinum crucible which discharges molten glass droplets through a platinum tube. The falling droplets sensed by a photocell are caught in a horizontal mould and transferred to a miniatured water cooled press. The pressed pieces are annealed to relieve the stresses. The annealed glasses are subjected to differential thermal analysis (DTA) to determine the nucleation $T_{N}$ and growth $T_{G}$ temperatures of various crystalline phases which would precipitate during ceramization of the glass (Herczog 1964; Bergeron and Russel 1965; Layton and Herczog 1967). A typical DTA plot of a glass (21 PbO-21 BaO-42 $\mathrm{TiO}_{2}-6 \mathrm{SiO}_{2}-10 \mathrm{~B}_{2} \mathrm{O}_{3}$ mole\%) is shown in figure 1. The

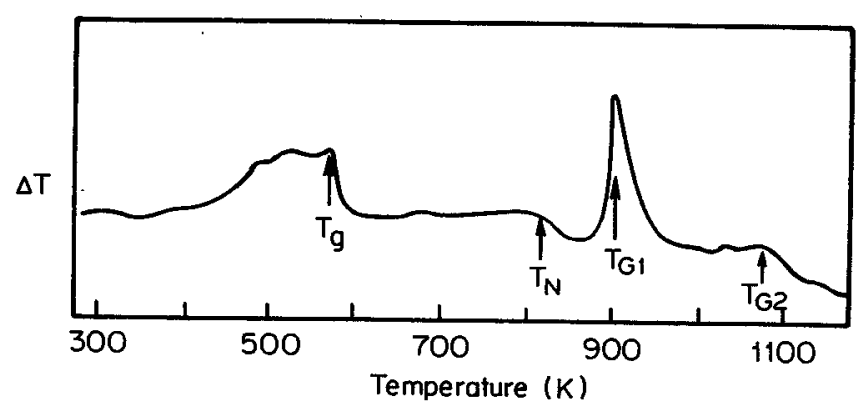

Figure 1. DTA curve for the glass in the system $\mathrm{BaO}-\mathrm{PbO}-\mathrm{TiO}_{2}-\mathrm{B}_{2} \mathrm{O}_{3}-\mathrm{SiO}_{2}(\mathrm{Om}$ Parkash et al 1986). 
first endotherm at $575 \mathrm{~K}$ represents the glass transition. The second endotherm at $810 \mathrm{~K}$ corresponds to nucleation of crystalline phases. The exothermic peaks at $900 \mathrm{~K}$ and $1075 \mathrm{~K}$ represent the growth temperatures $T_{G}$ of two phases respectively which are developed during heat treatment of this glass (Om Parkash et al 1986).

The glasses are then subjected to various heat treatment schedules based on DTA results. The crystalline phases precipitated during ceramization are identified by $\mathrm{x}$-ray diffraction (XRD) and their respective nucleation and growth temperatures are thus identified. In figure $1,900 \mathrm{~K}$ corresponds to the growth of $\mathrm{BaTiO}_{3}$, while $1075 \mathrm{~K}$. represents the growth of second crystalline phase. An optimum heat treatment schedule is determined based on the measurements of optical and electron microscopy and dielectric properties of the glass ceramics obtained by different heat treatment schedules.

When crystallization of glasses in the system $\mathrm{BaO}-\mathrm{TiO}_{2}-\mathrm{Al}_{2} \mathrm{O}_{3}-\mathrm{SiO}_{2}$ is carried out in reducing atmosphere, interconnected dispersion of semiconducting $\mathrm{BaTiO}_{3}$ in glassy matrix is obtained. Oxidation of this semiconductor leads to surface layers with very high dielectric strength and resistivity about 100 times higher than the resistivity obtained by direct crystallization of the glass in air (Herczog 1984).

\section{Systems}

As mentioned in $\S 1$, the ferroelectric phases which are precipitated during controlled crystallization of glasses in these glass ceramics are of $\mathrm{ABO}_{3}$ perovskite type. Ferroelectric glass ceramics studied can be put into two categories depending on the crystallite size and resulting properties: (1) those glass ceramics with crystallites having size $>0.1 \mu \mathrm{m}$. They are opaque and have potential applications as high permittivity materials, and (2) those with crystallites having size $<0 \cdot 1 \mu \mathrm{m}$. These glass ceramics are transparent and exhibit interesting electro-optic properties.

The different systems investigated are given in table $1 . \mathrm{BaTiO}_{3}$ and $\mathrm{PbTiO}_{3}$ crystals have been precipitated in different glass ceramic systems (Herczog 1964; Bergeron and Russell 1965). Solid solution ferroelectric ceramics possess more desirable properties than pure ferroelectric materials. Various attempts have been made to precipitate similar solid solution crystallites in the glass ceramics. Formation of pure lead titanate has been reported during ceramization of various glasses in the system $\mathrm{PbO}-\mathrm{BaO}-\mathrm{TiO}_{2}-\mathrm{B}_{2} \mathrm{O}_{3}-\mathrm{SiO}_{2}$ (Grossman and Isard 1969a, b; Lynch and Shelby 1984). However, $\mathrm{BaTiO}_{3}$ was obtained in the same system (Rajgopalan 1985). From these studies it is concluded that the ratio of $\mathrm{PbO}$ to $\mathrm{BaO}$ and $(\mathrm{PbO}+\mathrm{BaO})$ to $\mathrm{TiO}_{2}$ determines whether $\mathrm{PbTiO}_{3}$ or $\mathrm{BaTiO}_{3}$ would precipitate out during heat treatment. Other substitutions such as $\mathrm{Sr}$ for $\mathrm{Ba}$ and $\mathrm{Zr}$ for Ti result in precipitation of different phase rather than solid solutions. Formation of crystallites of various ferroelectric niobates and tantalates in the pure and the solid solution form over wide ranges of composition has been reported in glass ceramic systems (Borrelli 1967; Borrelli and Layton 1971) as shown in table 1. Most of these glass ceramics can be obtained with crystallite size $<0.1 \mu \mathrm{m}$ and are optically transparent. Thin crystals having large surface area have been obtained by glass ceramic processing in the system $\mathrm{Pb}_{5} \mathrm{Ge}_{3-x} \mathrm{Si}_{x} \mathrm{O}_{11}$ (Takahashi 1975). 
Table 1. Glass ceramic systems containing ferroelectric phases.

\begin{tabular}{|c|c|c|}
\hline Glass system & Ferroelectric phase & Reference \\
\hline $\mathrm{BaO}-\mathrm{TiO}_{2}-\mathrm{SiO}_{2}-\mathrm{B}_{2} \mathrm{O}_{3}$ & $\mathrm{BaTiO}_{3}$ & Herczog (1964) \\
\hline $\mathrm{BaO}-\mathrm{TiO}_{2}-\mathrm{SiO}_{2}-\mathrm{Al}_{2} \mathrm{O}_{3}$ & $\mathrm{BaTiO}_{3}$ & Herczog (1984) \\
\hline $\mathrm{PbO}-\mathrm{TiO}_{2}-\mathrm{B}_{2} \mathrm{O}_{3}$ & $\mathrm{PbTiO}_{3}$ & $\begin{array}{l}\text { Bergeron and Russell } \\
\text { (1965) }\end{array}$ \\
\hline $\mathrm{PbO}-\mathrm{TiO}_{2}-\mathrm{Al}_{2} \mathrm{O}_{3}-\mathrm{SiO}_{2}$ & $\mathrm{PbTiO}_{3}$ & $\begin{array}{l}\text { Kokubo and Tashiro } \\
(1973 / 74)\end{array}$ \\
\hline $\mathrm{PbO}-\mathrm{BaO}-\mathrm{TiO}_{2}-\mathrm{B}_{2} \mathrm{O}_{3}$ & $\mathrm{PbTiO}_{3}$ & $\begin{array}{l}\text { Lynch and Shelby } \\
\text { (1984) }\end{array}$ \\
\hline $\mathrm{PbO}-\mathrm{BaO}-\mathrm{TiO}_{2}-\mathrm{B}_{2} \mathrm{O}_{3}-\mathrm{SiO}_{2}-\mathrm{Al}_{2} \mathrm{O}_{3}$ & $\mathrm{PbTiO}_{3}$ & $\begin{array}{l}\text { Grossman and Isard } \\
(1969 \mathrm{a}, \mathrm{b})\end{array}$ \\
\hline $\mathrm{PbO}-\mathrm{BaO}-\mathrm{TiO}_{2}-\mathrm{B}_{2} \mathrm{O}_{3}-\mathrm{SiO}_{2}$ & $\mathrm{BaTiO}_{3}$ & $\begin{array}{l}\text { Om Parkash et al } \\
\text { (1986) }\end{array}$ \\
\hline $\mathrm{Na}_{2} \mathrm{O}-\mathrm{Nb}_{2} \mathrm{O}_{5}-\mathrm{SiO}_{2}$ & $\mathrm{NaNbO}_{3}$ & $\begin{array}{l}\text { Layton and Herczog } \\
\text { (1967) }\end{array}$ \\
\hline $\mathrm{CdO}-\mathrm{Na}_{2} \mathrm{O}-\mathrm{Nb}_{2} \mathrm{O}_{5}-\mathrm{SiO}_{2}$ & $\mathrm{Na}_{1-x} \mathrm{Cd}_{x / 2} \mathrm{NbO}_{3}$ & $\begin{array}{l}\text { Layton and Smith } \\
\text { (1975); Borrelli and } \\
\text { Layton (1971) }\end{array}$ \\
\hline $\mathrm{PbO}-\mathrm{Na}_{2} \mathrm{O}-\mathrm{Nb}_{2} \mathrm{O}_{5}-\mathrm{SiO}_{2}$ & $\mathrm{Na}_{1-x} \mathrm{~Pb}_{x / 2} \mathrm{NbO}_{3}$ & $\begin{array}{l}\text { Borrelli and Layton } \\
\text { (1971) }\end{array}$ \\
\hline $\begin{array}{l}\mathrm{Na}_{2} \mathrm{O}-\mathrm{K}_{2} \mathrm{O}-\mathrm{Nb}_{2} \mathrm{O}_{5}-\mathrm{SiO}_{2} \\
\mathrm{SrO}-\mathrm{Na}_{2} \mathrm{O}-\mathrm{Nb}_{2} \mathrm{O}_{5}-\mathrm{SiO}_{2} \\
\mathrm{PbO}-\mathrm{MgO}-\mathrm{Nb}_{2} \mathrm{O}_{5}-\mathrm{SiO}_{2} \\
\mathrm{SrO}-\mathrm{K}_{2} \mathrm{O}-\mathrm{Nb}_{2} \mathrm{O}_{5}-\mathrm{SiO}_{2} \\
\mathrm{Li}_{2} \mathrm{O}-\mathrm{Na}_{2} \mathrm{O}-\mathrm{K}_{2} \mathrm{O}-\mathrm{Nb}_{2} \mathrm{O}_{5}-\mathrm{SiO}_{2} \\
\mathrm{BaO}-\mathrm{CaO}-\mathrm{PbO}-\mathrm{Nb}_{2} \mathrm{O}_{5}-\mathrm{SiO}_{2} \\
\mathrm{BaO}-\mathrm{SrO}-\mathrm{PbO}-\mathrm{Nb}_{2} \mathrm{O}_{5}-\mathrm{SiO}_{2} \\
\mathrm{Li} \mathrm{Oi}_{2} \mathrm{O}-\mathrm{Na}_{2} \mathrm{O}-\mathrm{K}_{2} \mathrm{O}-\mathrm{Ta}_{2} \mathrm{O}_{5}-\mathrm{SiO}_{2} \\
\mathrm{PbO}-\mathrm{GeO}_{2}-\mathrm{SiO}_{2}\end{array}$ & $\begin{array}{l}\mathrm{Na}_{1-x} \mathrm{~K}_{x} \mathrm{NbO}_{3} \\
\mathrm{Na}_{1-x} \mathrm{Sr}_{x / 2} \mathrm{NbO}_{3} \\
\mathrm{~Pb}_{3} \mathrm{MgNb}_{5} \mathrm{O}_{9} \\
\mathrm{Sr}_{2} \mathrm{KNbO}_{5} \\
\mathrm{Li}_{x} \mathrm{Na}_{3} \mathrm{~K}_{2} \mathrm{NbO}_{3} \\
\mathrm{Ba}_{x} \mathrm{Ca}_{3} \mathrm{~Pb}_{2} \mathrm{Nb}_{2} \mathrm{O}_{6} \\
\mathrm{Ba}_{x} \mathrm{Sr}_{2} \mathrm{~Pb}_{2} \mathrm{Nb}_{2} \mathrm{O}_{6} \\
\mathrm{Li}_{x} \mathrm{Na}_{3} \mathrm{~K}_{z} \mathrm{Ta}_{2} \mathrm{O}_{6} \\
\mathrm{~Pb}_{3} \mathrm{Si}_{x} \mathrm{Ge}_{3-x} \mathrm{O}\end{array}$ & $\begin{array}{l}\text {-do- } \\
\text {-do- } \\
\text {-do- } \\
\text {-do- } \\
\text {-do- } \\
\text {-do- } \\
\text {-do- } \\
\text {-do- } \\
\text { Takahashi et al } 1975\end{array}$ \\
\hline
\end{tabular}

\section{Nucleation and crystallization}

An understanding of the mechanism of nucleation and crystallization in these glasses helps in better control of properties of resulting glass ceramics. Bergeron and Russell (1965) investigated the rate of growth of $\mathrm{PbTiO}_{3}$ crystals from a $\mathrm{PbO}-\mathrm{TiO}_{2}-\mathrm{B}_{2} \mathrm{O}_{3}$ glass at different temperatures. The Brown-Ginell equation satisfactorily explained the growth rate data. It was also observed that temperature of maximum growth rate was $100-150^{\circ} \mathrm{C}$ above the exotherm associated with the growth of lead titanate crystals in DTA plots of solid and powdered glass samples. It was ascribed to the large surface area of the powdered sample. The large number of nuclei present in such samples may result in a large heat effect even at low growth rate at the temperature of the exotherm. Most of the total quantity of the crystals which can be in equilibrium at the higher temperatures were precipitated below the temperature of maximum growth rate.

The crystallization behaviour of glasses in the system $\mathrm{Na}_{2} \mathrm{O}-\mathrm{Nb}_{2} \mathrm{O}_{5}-\mathrm{SiO}_{2}$ has been investigated by measuring the viscosity, grain size and crystalline content as a function of temperature at different constant heating rates (Layton and Herczog 1967). The crystallization was very rapid and exothermic, making the measurements at constant temperatures very difficult. From electron microscopic observations at various stages of heat treatments it was observed that in the beginning of crystalli- 
zation, particles of $500-1000 \AA$ in diameter appear in the glass. These particles were agglomerates of very fine crystallites of diameter $100 \AA$ or less. These fine crystallites constituting a particle, formed a star-like configuration indicating a growth from central nucleus. Slightly crystallized specimens also showed the presence of a large number of phase separated regions of $20-50 \AA$ in diameter. On further heating, these regions subsequently coalesced until a critical size was reached forming a stable nucleus. At low $\mathrm{SiO}_{2}$ content, uniform and very large concentration of these nuclei are formed indicating a high rate of nucleation. The transformation of the glass to the crystalline phase is complete with minimum of grain growth and sintering. Thus the final glass ceramic product is transparent due to crystallite size being less than $0.1 \mu \mathrm{m}$. At high $\mathrm{SiO}_{2}$ content, the nucleation rate is slower resulting in growth of crystals upto $1 \mu \mathrm{m}$ or more in diameter making the glass ceramic opaque.

Phase separation occurring during heat treatment may be due to the microheterogeneities in the structure of glass having the same size and composition as the phase separated regions. This can be understood in terms of the ratio of number $B$ of multivalent cations (such as $\mathrm{Ti}^{4+}$ and $\mathrm{Nb}^{5+}$ ) and network forming cations $\mathrm{N}$ (such as $\mathrm{Si}^{4+}, \mathrm{B}^{3+}, \mathrm{Al}^{3+}$ etc) present in the initial glass composition (Layton and Herczog 1969). The randomness of the glass network is attributed to flexibility of Si-O-Si bond angle or to that of angle formed by other network formers. $\mathrm{Ti}^{4+}$ and $\mathrm{Nb}^{5+}$ are normally octahedrally coordinated to oxygen in oxide lattices and they can replace the network forming ions upto a certain limit in oxide glasses. These ions lack flexibility of bond angles. When these cations are not associated with a true network former as their nearest neighbours, they become structurally ordered with respect to each other. These structurally ordered regions represent microheterogeneities in the glass structure. It is reasonable to assume that the ratio $B / N=1$ represents the limit of substitution of network forming cations by these ions without causing major structural inhomogeneities in the glass. As the ratio exceeds 1 , microheterogeneities are formed and on heating, phase-separated regions are produced in sufficient concentration, approaching the size of a stable nucleus allowing rapid interaction between them. This explains high rate of nucleation and rapid completion of crystallization without substantial grain growth in glasses with low network forming content.

The DTA curve in figure 1 shows the presence of second exothermic peak representing the growth of another crystalline phase beside barium titanate. Therefore, when the glass or the glass ceramic samples are heated at higher temperature (growth temperature of second phase) the second phase separates out along with $\mathrm{BaTiO}_{3}$. This is shown in the scanning electron micrograph (figure 2) of the glass ceramic sample obtained by heat treatment at this temperature (Om Parkash et al 1986). In order to obtain the maximum recovery of a ferroelectric phase during ceramization, it is recommended to start with a glass composition corresponding to stoichiometric composition of two crystal phases; the ferroelectric phase and a secondary phase containing all network forming additions. Presence of any residual glass reduces the yield of ferroelectric phase either by keeping it in solution or by secondary high temperature reaction with it (Herczog 1984).

\section{Electrical properties}

Uniform fine-grained microstructure is very desirable in ferroelectric ceramics as it imparts mechanical and dielectric stability suitable for various device applications. 


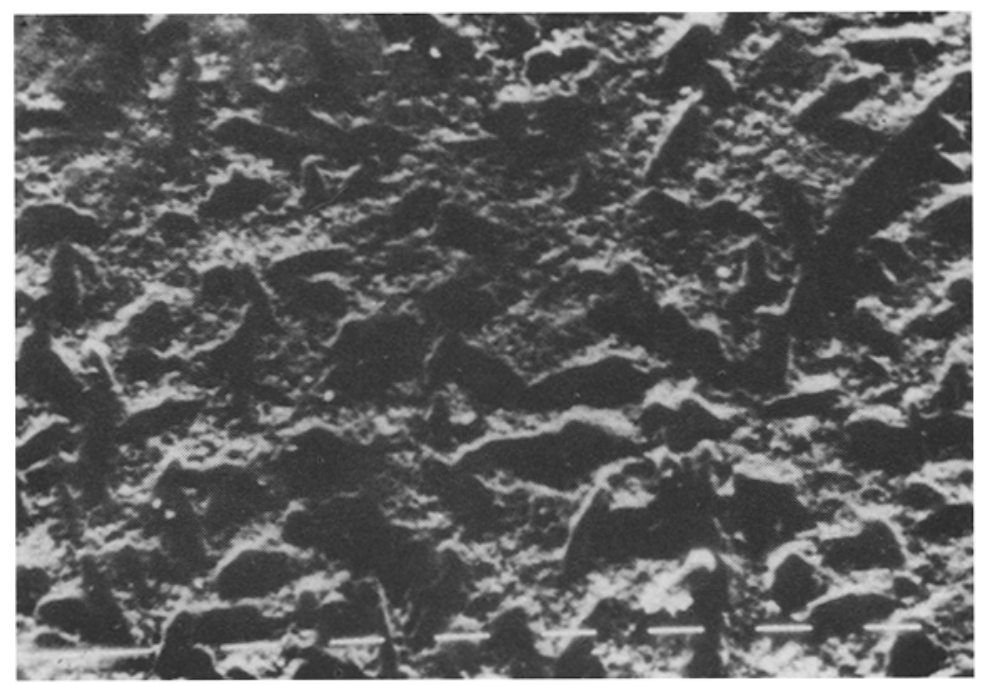

Figure 2. Microstructure of the glass ceramiss in the system $\mathrm{PbO}-\mathrm{BaO}-\mathrm{TiO}_{2}-\mathrm{B}_{2} \mathrm{O}_{3}-\mathrm{SiO}_{2}-$ $\mathrm{P}_{2} \mathrm{O}_{5}$, heat treated at $975 \mathrm{~K}$ for 12 hours. $-10 \mu \mathrm{m}$ (Om Parkash et al 1986).

This type of microstructure can be easily produced in ferroelectric glass ceramics by controlled heat treatment. The dielectric constant depends on the particle size and content of crystalline phase in these materials. A high percentage (75-80 volume\%) of a ferroelectric phase can be obtained starting with a suitable composition.

Variation of dielectric constant and loss tangent with temperature at $1 \mathrm{kHz}$ with $\mathrm{BaTiO}_{3}$ content and particle size is shown in figure 3 (Herczog 1964). The curves on the left side show the characteristics of the materials containing different percentages of $\mathrm{BaTiO}_{3}$ but having the same particle size. The right side curves are for materials of different particle size and of same barium titanate content. Dielectric anomaly was distinctly seen in samples having particle size $\geqslant 0.8 \mu \mathrm{m}$ (curves (a), (b) and (c)) becoming diffuse with decreasing particle size (curves (d) and (e)) and disappear completely below $0.1 \mu \mathrm{m}$. A maxima in dielectric constant as a function of grain size at $0.8 \mu \mathrm{m}$ was observed. A similar maxima in dielectric constant of microcrystalline $\mathrm{PbTiO}_{3}$ crystallized from $\mathrm{PbO}-\mathrm{TiO}_{2}-\mathrm{Al}_{2} \mathrm{O}_{3}-\mathrm{SiO}_{2}$ glass was observed at a grain size of $0 \cdot 15 \mu \mathrm{m}$ (Kokubo and Tashiro 1973/74). Similar dielectric behaviour has been reported in glass ceramics containing $\mathrm{NaNbO}_{3}$ (Borrelli and Layton 1971).

This dielectric behaviour as a function of crystallite size has been explained in terms of internal stresses generated in these submicrometer range crystallites and suppression of ferroelectric-to-paraelectric transition due to crystal clamping in the rigid surrounding glass matrix. This model was proposed by Buessem et al (1966) to explain the high permittivity in fine-grained $\mathrm{BaTiO}_{3}$. Kokubo and Tashiro (1973/74) through careful experimentation using XRD showed that the maximum dielectric constant was obtained at the same grain size at which the two-dimensional stress was maximum. The decrease in dielectric constant at higher grain size was ascribed to $90^{\circ}$ twinning within the grain as proposed by Buessem et al (1966), which leads to reduction in two-dimensional stresses. Similarly, temperature-independent behaviour for submicron range can be understood due to the absence of domain walls in these 


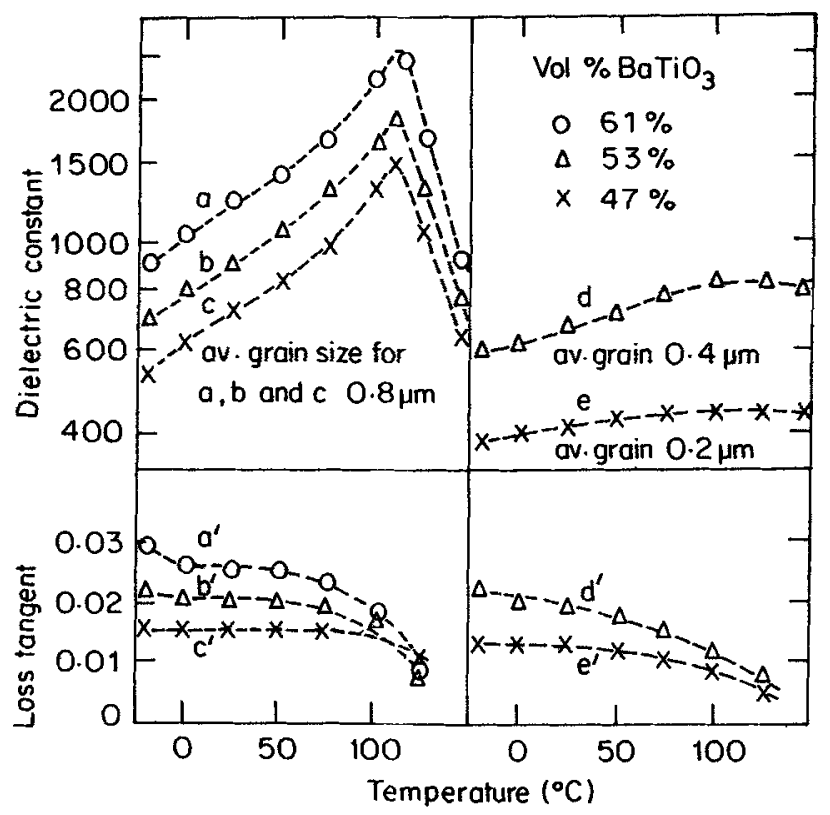

Figure 3. Variation of dielectric constant and loss tangent with temperature at $1 \mathrm{kHz}$ for glass ceramics containing different contents and size of $\mathrm{BaTiO}_{3}$ crystallites (Herczog 1964).

crystallites. For particles $\geqslant 1 \mu \mathrm{m}$ or so, $90^{\circ}$ twinning of domain wall becomes possible and hence glass ceramics containing particles in this range show a normal dielectric anomaly at the Curie point.

These glass ceramics show a higher dielectric breakdown strength and resistivity as compared to normally-sintered ferroelectric ceramics due to absence of porosity.

When the crystallite size in these glass ceramics is $\leqslant 0: 1 \mu \mathrm{m}$, they become transparent and exhibit interesting electro-optic properties. A quadro-electro optic effect is observed when an electric field $E$ is applied on the as crystallized glass ceramics. The induced birefringence $\Delta n_{2}$ is expressed by the equation

$$
\Delta n_{2}=\frac{1}{2} n^{3} g \varepsilon^{2} E^{2}
$$

where $n, g$ and $\varepsilon$ are the refractive index, electro-optic coefficient and dielectric constant of the glass ceramic. When an electric field is applied on the prepoled glass ceramic, however, a linear electro-optic effect is observed and the induced birefringence $\Delta n_{1}$ is expressed by

$$
\Delta n_{1}=\frac{1}{2} n^{3} g P_{1} \& E
$$

where $P_{1}$ is the remanent polarization of the glass ceramic. The ferroelectric-paraelectric transition is suppressed below the crystallite size of $0.1 \mu \mathrm{m}$. This also represents the upper limit upto which these materials are transparent. Therefore, a linear electro-optic effect cannot be observed in these transparent materials. However, they have a large value of dielectric constant even when the particle size is $<0.1 \mu \mathrm{m}$. Therefore, a large quadro-electro-optic effect is observed (Borrelli 1967; Borrelli and Layton 1971).

Observation of a hysteresis loop between polarization and applied electric field is 
the true test of the presence of ferroelectricity in a given material. Fully developed hysteresis loops have been observed for glass ceramics containing crystallites having size $>1 \mu \mathrm{m}$ while some hysteresis effects have been observed down to $0.2 \mu \mathrm{m}$ (Herczog 1964). For transparent glass ceramics containing particles having size $<0 \cdot 1 \mu \mathrm{m}$, no hysteresis loops were observed and it can be understood by the absence of domain walls in these small crystallites (Borrelli and Layton 1971). However, the pyroelectric measurements on these glass ceramics show that the sign of the pyroelectric signal reversed on the reversal of the maximum bias field, a positive proof of reversible spontaneous polarization, establishing ferroelectricity in transparent glass ceramics (Layton and Smith 1975).

\section{Conclusions}

Glass ceramics containing a variety of ferroelectric phases can be produced with a precise control of microstructure. The value of dielectric constant can be varied by controlling the crystal content and its size. A high and an almost temperatureindependent value of dielectric constant is obtained for crystallite size in the submicron range. If the crystallite size is $<0.1 \mu \mathrm{m}$, these are optically transparent and exhibit a large quadratic electro-optic effect. These characteristics make them potentially useful in various electronic components and devices in different forms (Kokubo et al 1968; Herczog 1973; Devendra Kumar and Om Parkash 1985).

Various attempts to precipitate ferroelectric crystallites in the solid solution form to obtain improved properties have not yielded any encouraging results in the case of titanates. Though the formation of extensive solid solution in niobates and tantalates in glass ceramics have been reported, yet no conclusive evidence is given in its support. Therefore problems associated with precipitation of solid solution ferroelectric crystallites in the glass ceramics require detailed investigations. This problem, if solved, will enhance the utilization of ferroelectric glass ceramics.

\section{References}

Bergeron C G 1961 Crystallization of perovskite lead titanate from glass, Ph.D. Thesis, University of Illinois

Bergeron C G and Russell C K 1965 J. Am. Ceram. Soc. 48115

Borrelli N F 1967 J. Appl. Phys. 384243

Borrelli N F, Herczog A and Maurer R D 1965 Appl. Phys. Lett. 7117

Borrelli N F and Layton M M 1971 J. Non-Cryst. Solids 6197

Buessem W A, Cross L E and Goswami A K 1966 J. Am. Ceram. Soc. 4933

Devendra Kumar and Om Parkash 1985 Ferroelectric glass ceramics, Symposium on Emerging Frontiers in Ceramic Engineering, Banaras Hindu University, Varanasi

Glass A M, Nassau K and Negram T J 1978 J. Appl. Phys. 494808

Grossman D G and Isard J O 1969a J. Am. Ceram. Soc. 52230

Grossman D G and Isard J O 1969b J. Mater. Sci. 41059

Herczog A 1964 J. Am. Ceram. Soc. 47107

Herczog A 1967 Glass Ind. 48455

Herczog A 1973 IEEE Trans PHP 9247

Herczog A 1984 J. Am. Ceram. Soc. 67484

Kokubo T, Kung C T and Tashiro M 1968 J. Ceram. Assn. Jpn. 7689

Kokubo T and Tashiro M 1973/74 J. Non-Cryst. Solids 13328

Layton M M and Herczog A $1967 \mathrm{~J}$. Am. Ceram. Soc. 50369

Layton M M and Herczog A 1969 Glass Technol. 1050 
Layton M M and Smith J W 1975 J. Am. Ceram. Soc. 58435

Lynch S M and Shelby J E 1984 J. Am. Ceram. Soc. 67424

McMillan P W 1979 Glass ceramics (2nd ed) (London: Academic Press)

Nassau K, Wang C A and Grasso M 1979a J. Am. Ceram. Soc. 6274

Nassau K, Wang C A and Grasso M 1979b J. Am. Ceram. Soc. 62503

Nassau K, Cava R J and Glass A M 1981 Solid State Ionics 2163

Om Parkash, Devendra Kumar and Rajgopalan R 1986 Bull. Mater. Sci. 813

Rajgopalan R 1985 Preparation and characterization of glass ceramic containing ferroelectric phase, M.Tech. Thesis, Institute of Technology, Banaras Hindu University

Stookey S D 1959 Glasstech. Ber. 32K (Fifth International congress on glass, Verlag der Deutschen Glastechnischen Gesellschaft, Frankfurt am Main) p 574

Takahashi K, Cross L E and Newnham R E 1975 Mater. Res. Bull. 10599

Ulrich D R and Smoke E J 1966 J. Am. Ceram. Soc. 49210 